\title{
Research Article \\ Self-Medication in University Students from the City of Mansoura, Egypt
}

\author{
R. M. Helal and H. S. Abou-ElWafa \\ Public Health and Community Medicine Department, Faculty of Medicine, Mansoura University, Mansoura, Egypt \\ Correspondence should be addressed to H. S. Abou-ElWafa; halsam2005@gmail.com
}

Received 8 December 2016; Revised 23 February 2017; Accepted 8 March 2017; Published 5 April 2017

Academic Editor: Linda M. Gerber

Copyright (c) 2017 R. M. Helal and H. S. Abou-ElWafa. This is an open access article distributed under the Creative Commons Attribution License, which permits unrestricted use, distribution, and reproduction in any medium, provided the original work is properly cited.

\begin{abstract}
Background. Self-medication is a common practice in developed and developing countries. Objectives. To explore the prevalence of self-medication practices among university students, probable reasons, symptoms requiring self-medication, and sources of advice. Methods. A descriptive cross-sectional study was carried out in Mansoura University, Egypt, and included 1st and last year students of both medical and nonmedical faculties. Results. Prevalence of self-medication was $62.9 \%$. Younger age, female, medical, and ever-married students and those having home pharmacy tended to self-medicate more than their peers with significant difference between them. Being medical student, being from urban area, having good current health condition, being careless about health, and having drugs stored at home pharmacy were independently associated with the likelihood of self-medicating. Conclusion. Prevalence of self-medication among university students is high which constitutes a health problem that needs intervention.
\end{abstract}

\section{Introduction}

Self-medication is defined as getting and consuming drug without the guidance of physician for either diagnosis, treatment, or supervision of the treatment [1] generally involving over-the-counter (OTC) medications but also including prescription-only medicines (POM) [2], at the same time it includes buying drugs by reutilizing/resubmitting a previous prescription, taking medicines on advice of relative or others, or consuming leftover medicines already available at home [3].

Self-medication with OTC medications is a worldwide public health problem [4] and is more experienced in developing countries [5]. Self-medication patterns vary among different populations and are influenced by various features, such as age, gender, income and expenditure, self-care orientation, educational level, medical knowledge, satisfaction, and nonseriousness of illnesses $[6,7]$.

Studies revealed that self-medication represents a common problem among university students $[3,8,9]$. Media exposure and the increase of pharmaceuticals advertisement pose a larger threat to this population as it was found that majority of college students used at least one of the advertised products, without discussing it with their physicians [10]. Other reasons for self-medication among university students were their previous experiences, advice of family or friends, their health problems being considered as too trivial, time saving, nonavailability of transport, convenience, ability to self-manage the symptoms, urgency of the problem, doctor that was not available, and having sufficient information $[9,11$, 12]. Lack of time, low cost consultation, and trust in medical doctor were reported as main reasons in other studies $[8,13]$.

Self-medication when practiced correctly reduces the load on medical services, reduces the time spent in waiting to see the physician, and saves cost especially in economically deprived countries with limited healthcare resources [14].

However, it has been found that self-medication can slip towards self-medication with prescription medications and/or improper drug use such as misdiagnosis, low or high doses, and/or treatment duration. Such practices may result in irrational drug use [15], delayed seeking of medical advice, and increased side effects and increase in pathogens resistance that result in wasting of resources [16].

Despite the importance of the problem of self-medication among university students, to authors' knowledge, only two 
Egyptian studies investigated that problem, one among medical students in Ain Shams University [17] and the other among nonmedical students in Suez Canal University [18].

So, the main objectives of this study were to explore: (1) prevalence of self-medication practices among university students (medical and nonmedical); (2) the most probable determinants for such practices; (3) types of medications used; and (4) sources of advice for self-medication.

\section{Subjects and Methods}

2.1. Study Population. A descriptive cross-sectional study was carried out in Mansoura University, Egypt, and included 1st and last year students of both medical (medicine, pharmacy, an nursing) and nonmedical (commerce and education) colleges during the academic year 2014-2015.

2.2. Sample Size Determination. Sample size was calculated online (https://www.dssresearch.com/). From a previous study [17] in Ain Shams University, Egypt, the prevalence of self-medication was found to be $55 \%$ and by considering the worst acceptable value as $50 \%$; the sample size was 614 with $95 \%$ confidence level and $80 \%$ study power. The calculated sample size was multiplied by 1.5 to compensate for the design effect of the cluster sampling technique employed. Thus, the final sample size was about 900 .

2.3. Sampling Technique. A multistage, stratified, cluster sampling technique was adopted. In the first stage, the university colleges were stratified into medical (medicine, dentistry, pharmacy, nursing, and veterinary) and nonmedical (engineering, education, physical education, commerce, agriculture, law, and arts). The sample size was distributed proportionally between both categories. In the second stage, one college or more was selected from each group by lottery method. Lastly, in each college, students were stratified into first and last academic years. From each stratum, a section (cluster) was randomly chosen. All students in the chosen clusters were included. A total of 900 students were registered in 20 chosen clusters (30-40 students in each cluster).

A total of 900 questionnaires were distributed and 800 questionnaires were returned back making a response rate of $89 \%$ due to absence of some students during the study period (3.8\%), incomplete questionnaires (5\%), and lack of interest in the study $(2.2 \%)$.

2.4. Study Tool. A semistructured questionnaire was used to collect the following data: sociodemographic characteristics, for example, age, sex, residence, marital and working statuses, college, grade, and mother and father age and education; health-related questions, for example, use of any illicit (illegal) drug, care about health, current health status, last medical consultation, drugs stored at home, and treatment with or without medical supervision; self-medication practices including conditions in which the students believe that self-medication is convenient, drugs used, reasons for self-medication, source of advice, and advantage and disadvantage of self-medication; and knowledge about drugs: for example, antibiotics strengthen the immune system and some medications can be absorbed into the bloodstream through the skin.

2.5. Ethical Consideration. This study was approved by both the Vice Dean of the Students' Affairs and the Institutional Research Board (IRB) at Faculty of Medicine, Mansoura University. An informed verbal consent of study subjects, to participate voluntarily in the study with a full right to withdraw, was obtained with assurance of confidentiality and anonymity of the data.

2.6. Data Analysis. Data were entered and statistically analyzed using the Statistical Package for Social Sciences (SPSS) version 16. Qualitative data were described as numbers and percentages. Chi-square $\left(\chi^{2}\right)$ test was used for comparison between groups. Quantitative data were described as means (SD) after testing of normality by Kolmogorov-Smirnov test. Independent sample $t$-test was used for comparison between groups. Binary stepwise logistic regression analysis was used for prediction of independent variables of selfmedication. Significant predictors in the univariate analysis were entered into the regression model. Odds ratios and their $95 \%$ confidence interval were calculated. " $p$ value $\leq 0.05$ ” was considered to be statistically significant in the univariate and multivariate analyses.

\section{Results}

The mean age of students was $20 \pm 0.7$ years with a higher mean age of the father than the mother (53.3 and 45.5 years, resp.). Most of the students were females (78.1\%) and the majority (91\%) were ever married, with nearly equal distribution regarding their residence; the medical sector represented $52 \%$ while $48 \%$ were nonmedical; about $60 \%$ were in their last grade with the most frequent education of their father and mother being university and higher level (data are not shown in tables).

About $61 \%$ of students reported that their current health condition was good while only $45.1 \%$ were careful regarding their degree of care about health, and most (77.5\%) stored drugs at their home pharmacy. The most frequent conditions that are suitable for self-medication from the students opinion were cold $(70.1 \%)$, headache $(58.9 \%)$, sore throat $(35.8 \%)$, intestinal colic (32.2\%), and then cramps (31\%). About $59 \%$ of students mentioned that the self-medicated drugs solved the symptom (Tables 1 and 2).

The prevalence of self-medication was $62.9 \%$. The most frequently reported cause of self-medication was "no need to visit the doctor for a minor disease" followed by "knowledge from previous experience" (73.9\% and $71.4 \%$, resp.) and the least was "unavailability of health service," while fear of adverse/side effects was the most frequent cause to not selfmedicate. Pharmacy clerk (69.9\%) and neighbors and family $(62.2 \%)$ were the most frequently reported sources for selfmedication compared to friends and classroom colleagues $(0.6 \%)$ and old prescription (33.6\%), their own decision represented $30.2 \%$, and the Internet constituted $29.4 \%$. As regards the academic effect on self-medication, $61.8 \%$ of 
TABLE 1: Health-related information of students.

\begin{tabular}{lcc}
\hline Information & $N$ & $\%$ \\
\hline Current health condition & & \\
$\quad$ Excellent & 486 & 10.5 \\
$\quad$ Good & 230 & 60.8 \\
$\quad$ Fair & & 29.2 \\
Degree of care about health & 361 & \\
$\quad$ Careful & 439 & 45.1 \\
$\quad$ Careless & 620 & 54.9 \\
Drug storage at home pharmacy & 800 & 77.5 \\
\hline Total & \\
\hline
\end{tabular}

TABLE 2: Reasons for self-medication among medical and nonmedical students.

\begin{tabular}{|c|c|c|}
\hline System & $N$ & $\%$ \\
\hline \multicolumn{3}{|l|}{ Respiratory } \\
\hline Cold & 561 & 70.1 \\
\hline Sore throat & 286 & 35.8 \\
\hline Cough & 227 & 28.4 \\
\hline \multicolumn{3}{|l|}{ Gastrointestinal } \\
\hline Intestinal colic & 258 & 32.2 \\
\hline Diarrhea & 225 & 28.1 \\
\hline Constipation & 201 & 25.1 \\
\hline Heartburn & 172 & 21.5 \\
\hline Vomiting & 154 & 19.2 \\
\hline Poor digestion & 104 & 13.0 \\
\hline Liver problems & 39 & 4.9 \\
\hline \multicolumn{3}{|l|}{ Pain \& musculoskeletal } \\
\hline Cramps & 248 & 31.0 \\
\hline Toothache & 164 & 20.5 \\
\hline Muscle pain & 64 & 8.0 \\
\hline Earache & 45 & 5.6 \\
\hline \multicolumn{3}{|l|}{ Neurological } \\
\hline Headache & 471 & 58.9 \\
\hline Sickness & 125 & 15.6 \\
\hline Sleep disorders & 64 & 8.0 \\
\hline Lack of attention & 28 & 3.5 \\
\hline Anxiety & 20 & 2.5 \\
\hline Tiredness & 17 & 2.1 \\
\hline \multicolumn{3}{|l|}{ Others } \\
\hline Allergy & 60 & 7.5 \\
\hline Fever & 41 & 5.1 \\
\hline Urinary tract infection & 24 & 3.0 \\
\hline Weight loss & 23 & 2.9 \\
\hline Skin rash & 22 & 2.8 \\
\hline The self-medicated drugs solved the symptom & 473 & 59.1 \\
\hline Total & 800 & \\
\hline
\end{tabular}

students gained knowledge which made them safer for selfmedication, and being more careful when self-medicating was the most frequent change in students' practice of selfmedication. Regarding recent attitude of students towards self-medication, reading the package leaflet of self-medicated drug was the most frequently reported (88.8\%) followed by discouraging friends and family from self-medicating (87.4\%) (Table 3).

About half of the students were knowledgeable that some medications could be absorbed into the bloodstream through the skin while only $11.6 \%$ of them had knowledge regarding drug interaction (data are not shown in tables).

As regards sociodemographic characters of the studied group, there was statistically significant difference between students who self-medicate and those who do not regarding student and father ages, gender, residence, education, marital status where most of the self-medicating group were females from urban areas, medical students, and ever-married students, and lastly paternal education where most of the self-medicating group belonged to families with secondary, university, and higher education. Concerning health-related factors, there was statistically significant difference between both groups regarding their current health condition, degree of care about health, and drug storage at home pharmacy where most of the self-medicating group mentioned good health condition, being careless about their health, and storing drugs at home pharmacy. Younger age, female, medical, ever-married students, and those having home pharmacy tended to self-medicate more than their peers with significant difference between them.

Logistic regression analysis showed that being from urban area, being medical student, having good current health condition, being careless about health, and having drugs stored at home pharmacy were independently associated with the likelihood of self-medicating $(\mathrm{OR}=1.4,2.2,2,0.5$, and 2.4, resp.) (Table 4).

\section{Discussion}

Prevalence of self-medication has remained common in both developing and developed countries [19, 20] and the trend is increasing among youths [21] and common among university students [22]. Socioeconomic factors, lifestyle, readily available drugs, increased medical consultation cost, time consuming clinical process, lack of nearby access to healthcare, past experiences, and extensive advertisement are some of the leading reasons for people seeking selfmedication $[8,13,23]$.

In this study, students had a mean age of $20 \pm 0.7$ years, $78.1 \%$ were female, about $60 \%$ were in their last grade, $52 \%$ belonged to the medical sector, and $77.5 \%$ of students stored drugs at their home pharmacy. Similarly in Karachi, the mean age of university students who participated in this study was $21 \pm 1.8$ years. Amongst them $51.6 \%$ were medical students while $48.4 \%$ were nonmedical. There were $41.1 \%$ males and $58.9 \%$ females. They obtained drugs mostly from a pharmacy $(64.6 \%)$ or/and stocks kept at home $(64.4 \%)$ or from friends (9.7\%) [3].

In our study, the most frequent conditions in which the student self-medicated were cold, headache, sore throat, intestinal colic, and lastly cramps. About 59\% of students mentioned that the self-medicated drugs solved the symptom. 
TABLE 3: Explanations for self-medication.

\begin{tabular}{|c|c|c|}
\hline Prevalence & $N$ & $\%$ \\
\hline Self-medication & 503 & 62.9 \\
\hline No self-medication & 297 & 37.1 \\
\hline \multicolumn{3}{|l|}{ Causes of self-medication (503) } \\
\hline No need to visit the doctor for a minor disease & 372 & 73.9 \\
\hline Knowledge from previous experience & 359 & 71.4 \\
\hline The doctor will prescribe me the same drug & 155 & 30.8 \\
\hline Time and money saving & 119 & 23.7 \\
\hline Fast relief & 66 & 13.1 \\
\hline Chance to have experience & 36 & 7.2 \\
\hline Absence of trust in health services & 27 & 5.4 \\
\hline Unavailability of health service & 15 & 2.9 \\
\hline \multicolumn{3}{|l|}{ Causes for not self-medicating $(297)^{\#}$} \\
\hline Fear of adverse/ side effects & 124 & 41.8 \\
\hline Lack of knowledge \& experience & 73 & 24.6 \\
\hline Lack of confidence & 52 & 17.5 \\
\hline It is injurious to health & 31 & 10.4 \\
\hline Prior bad experience with self-medication & 17 & 5.7 \\
\hline \multicolumn{3}{|l|}{ Sources for self-medication $(503)^{\#}$} \\
\hline Pharmacy clerk & 352 & 69.9 \\
\hline Neighbors \& family & 313 & 62.2 \\
\hline Friends \& classroom colleagues & 204 & 40.6 \\
\hline Old prescription & 169 & 33.6 \\
\hline My decision & 152 & 30.2 \\
\hline Internet & 148 & 29.4 \\
\hline Books \& magazine & 24 & 4.8 \\
\hline \multicolumn{3}{|l|}{ Academic effect on self-medication: } \\
\hline $\begin{array}{l}\text { (i) knowledge gained in college makes students } \\
\text { safer for self-medication }\end{array}$ & 494 & 61.8 \\
\hline \multirow{2}{*}{\multicolumn{3}{|c|}{$\begin{array}{l}\text { (ii) Changes observed in practice of } \\
\text { self-medication as the students acquire more } \\
\text { academic knowledge }^{\#}\end{array}$}} \\
\hline & & \\
\hline More careful when I self-medicate & 313 & 39.1 \\
\hline $\begin{array}{l}\text { More concerned about adverse effects/side } \\
\text { effects/interactions }\end{array}$ & 180 & 22.5 \\
\hline More confident self-medicating & 133 & 16.6 \\
\hline No change & 86 & 10.8 \\
\hline I would rather use a prescription & 75 & 9.4 \\
\hline \multicolumn{3}{|l|}{ (iii) Recent attitude towards self-medication ${ }^{\#}$} \\
\hline $\begin{array}{l}\text { Reading the package leaflet of self-medicated } \\
\text { drugs }\end{array}$ & 710 & 88.8 \\
\hline $\begin{array}{l}\text { I discourage friends and family from } \\
\text { self-medicating }\end{array}$ & 699 & 87.4 \\
\hline $\begin{array}{l}\text { Believe what they read in the leaflet of } \\
\text { medicinal products }\end{array}$ & 698 & 87.2 \\
\hline $\begin{array}{l}\text { I encourage friends and family to } \\
\text { self-medicate }\end{array}$ & 101 & 12.6 \\
\hline Total & 800 & \\
\hline
\end{tabular}

${ }^{\#}$ Categories are not mutually exclusive.

Similarly, the overall reasons for self-medication among university students from the city of Rio Grande, Brazil, were headache, cold, sore throat, fever, menstrual cramps, muscle pain, cough, and heartburn as well as stomachache, nausea, vomit, allergy, and intestinal colic [24]. In Karachi, the most common symptoms were headaches, fever, and flu-like symptoms [3]. In Abbottabad, Pakistan, the most common symptom was "storage of medicines for multipurposes" (50.8\%). This was followed by occasional pain, common infections, and cough/cold. About $67.2 \%$ of respondents were successfully treated by self-medication, while $33.7 \%$ experienced more severity in disease conditions [25].

In Nepal, fever, headaches, and cough were the predominant indications for self-medication among undergraduate pharmacy students followed by diarrhoea, cold, acidity, and pain condition. This was in accordance with that of the Association of European Self-Medication Industry which had enlisted pain, allergy, colds, sore throat, cough, and diarrhoea as common diseases for preferring self-medication [26].

This study showed that pharmacy clerk, neighbors, and family were the most frequently reported sources for selfmedication and lastly Internet. In Nepal, friends and family, chemist, and Internet were registered as top three sources of information by the undergraduate pharmacy students [26].

The prevalence of self-medication in this study was $62.9 \%$ with significantly higher prevalence in the medical sector than the nonmedical one $(72.4 \%$ and $52.6 \%$, resp.). Our finding was in accordance with that study in Karachi, where it was found to be $76 \%$ with no significant difference between medical and nonmedical students [3].

A higher prevalence of self-medication was reported by some studies. It was found to be $95.5 \%$ in Abbottabad, Pakistan, with statistically nonsignificant $(p=0.099)$ difference between health and nonhealth students [25]. In the city of Rio Grande, Brazil, $86.4 \%$ of university students reported self-medication, $58 \%$ were healthcare students, and $61 \%$ were first-year students [24]. It was found to be $88 \%$ in Croatia [27], 94\% in Hong Kong [28], 98\% in Palestine [8], and 92.3\% in Slovenia [9].

This could be explained by the fact that nonmedical students also consider themselves to be as knowledgeable about medicines as medical students, or it just may be that university students both medical and nonmedical do not care much about the implication of such behavior and thus do not hesitate to indulge in such activities [3].

A lower prevalence of self-medication was reported by some studies. In a Brazilian study, $57.7 \%$ of university students in the city of Recife declared not to self-medicate [29]. Also, it was found to be up to $45 \%$ in Turkey [30]. It may be explained that healthcare-related education of students led to more responsible self-medication [9].

The most frequently reported causes of self-medication were "no need to visit the doctor for a minor disease" and the least was "unavailability of health service," while "fear of adverse/side effects" was the most frequent cause for not self-medicating. In accordance with our results, in that study in Brazil, the first reason cited by university students was "I have already experienced the symptom and know what to take" (57.2\%) [24]. This may reflect a usual behavior and the repeated use of an old prescription. Storage of medications at home with free access and easy visualization of the drugs is a risk factor for self-medication [31]. Receiving advice mainly from the family (53.1\%) about self-medication and the reuse of old prescription (40.4\%) contribute to the risk posed by home pharmacies [24]. This suggests an easy access to medications and a culturally inherited acceptance of selfmedication [32]. Further explanations for self-medication cited by students in this study included "there is no need to 
TABLE 4: Adjusted and crude analysis of the variables associated with self-medication.

\begin{tabular}{|c|c|c|c|c|c|}
\hline & $\begin{array}{l}\text { Self-medicating } \\
\quad N=503\end{array}$ & $\begin{array}{c}\text { Not } \\
\text { self-medicating } \\
N=297\end{array}$ & $p$ value & $\begin{array}{c}\text { Univariate } \\
\text { analysis } \\
\text { OR (CI) }\end{array}$ & $\begin{array}{c}\text { Multivariate } \\
\text { analysis } \\
\text { OR (CI) }\end{array}$ \\
\hline \multicolumn{6}{|c|}{ Sociodemographic characters } \\
\hline Student age & $19.9 \pm 0.7$ & $20.1 \pm 0.7$ & 0.000 & & \\
\hline Mother age & $45.7 \pm 5.1$ & $45.1 \pm 5.1$ & 0.083 & & \\
\hline Father age & $53.9 \pm 12.2$ & $52.1 \pm 5.9$ & 0.02 & & \\
\hline \multicolumn{6}{|l|}{ Sex } \\
\hline Female & $411(65.8)$ & $214(34.2)$ & \multirow{2}{*}{0.002} & $1.7(1.2-2.4)$ & \\
\hline Male (R) & $92(52.6)$ & $83(47.4)$ & & & \\
\hline \multicolumn{6}{|l|}{ Residence } \\
\hline Urban & $274(68.2)$ & $128(31.8)$ & \multirow{2}{*}{0.002} & $1.6(1.2-2.1)$ & $1.4(1.1-1.9)$ \\
\hline Rural (R) & $229(57.5)$ & $169(42.5)$ & & & \\
\hline \multicolumn{6}{|l|}{ Education } \\
\hline Medical & $301(72.4)$ & $115(27.6)$ & \multirow{2}{*}{0.000} & $2.4(1.8-3.2)$ & $2.2(1.6-2.9)$ \\
\hline Nonmedical (R) & $202(52.6)$ & $182(47.4)$ & & & \\
\hline \multicolumn{6}{|l|}{ Father education } \\
\hline Illiterate (R) & $27(46.6)$ & $31(53.4)$ & & & \\
\hline Primary and preparatory & $57(54.8)$ & $47(45.2)$ & 0.31 & $1.4(0.7-2.8)$ & \\
\hline Secondary & $132(67.3)$ & $64(32.7)$ & 0.004 & $2.4(1.3-4.5)$ & \\
\hline University and higher & $287(64.9)$ & $155(35.1)$ & 0.006 & $2.1(1.2-3.8)$ & \\
\hline \multicolumn{6}{|l|}{ Mother education } \\
\hline Illiterate (R) & $42(47.2)$ & $47(52.8)$ & 0.16 & & \\
\hline Primary and preparatory & $52(57.8)$ & $38(42.2)$ & & $1.5(0.8-2.9)$ & \\
\hline Secondary & $149(62.6)$ & $89(37.4)$ & 0.011 & $1.9(1.1-3.2)$ & \\
\hline University and higher & $260(67.9)$ & $123(32.1)$ & 0.0002 & $2.4(1.4-3.9)$ & \\
\hline \multicolumn{6}{|l|}{ Marital status } \\
\hline Never married & $35(48.6)$ & $37(51.4)$ & \multirow{2}{*}{0.009} & $0.5(0.32-0.86)$ & \\
\hline Ever married (R) & $468(64.3)$ & $260(35.7)$ & & & \\
\hline \multicolumn{6}{|l|}{ Grades } \\
\hline 1st grades & $197(61.0)$ & $126(39.0)$ & \multirow{2}{*}{0.37} & $0.9(0.65-1.17)$ & \\
\hline Final grades $(\mathrm{R})$ & $306(64.2)$ & $171(35.8)$ & & & \\
\hline \multicolumn{6}{|c|}{ Health-related factors } \\
\hline \multicolumn{6}{|l|}{ Current health condition } \\
\hline Excellent & $46(54.8)$ & $38(45.2)$ & 0.9 & $1(0.6-1.6)$ & $1.3(0.74-2.3)$ \\
\hline Good & $329(67.7)$ & $157(32.3)$ & 0.002 & $1.7(1.2-2.3)$ & $2.0(1.4-2.9)$ \\
\hline Fair (R) & $128(55.7)$ & $102(44.3)$ & & & \\
\hline \multicolumn{6}{|l|}{ Degree of care about health } \\
\hline Careful & $204(56.5)$ & $157(43.5)$ & \multirow{2}{*}{0.001} & $0.61(0.5-0.8)$ & $0.5(0.4-0.9)$ \\
\hline Careless & $299(68.1)$ & $140(31.9)$ & & & \\
\hline \multicolumn{6}{|l|}{$\begin{array}{l}\text { Drug storage at home } \\
\text { pharmacy }\end{array}$} \\
\hline No & $78(49.7)$ & $79(50.3)$ & 0.58 & $1.28(0.5-3.4)$ & $1.3(0.5-3.4)$ \\
\hline Yes & 415 (66.9) & $205(33.1)$ & 0.02 & $2.6(1.1-6.6)$ & $2.4(1.0-5.9)$ \\
\hline I do not know (R) & $10(43.5)$ & $13(56.5)$ & & & \\
\hline
\end{tabular}

Model $\chi^{2}=82 \%, p<0.0001, \%$ correctly predicted $=67.8 \%$, and constant $=-0.974$.

see a doctor because of a simple disease" and "quick relief." These explanations could be supported also by the existence of home pharmacy [24].

In Nepal, it is to be noted that $36.47 \%$ perceived selfmedication as unacceptable practice while $47.64 \%$ said it was an acceptable practice. When asked about the reason where practicing self-medication would be considered unacceptable, seldom effectiveness (12.35\%), adverse reaction
(16.47\%), unsafe (37.46\%), and likely side effects $(18.23 \%)$ were the main reasons among undergraduate pharmacy students [26]. In Karachi, the most common factors that led to self-medication were "previous experience with similar symptoms" (50.1\%) and self-perception of "trivial nature of the problem" (48.3\%) [3].

However, in Abbottabad, Pakistan, the most common factor responsible for self-medication was "low severity of 
disease" (45.7\%) and the second most common factor was "told by doctor verbally" (44.9\%). Other causes of selfmedication were lack of access and time and financial issues [25].

In contradiction with our study, in Southwestern Nigeria, the issue of long waiting queues at clinics or hospitals was raised by $59 \%$ of university students as one of the reasons for seeking self-care in order to meet up with their tight lecture schedule [33].

About $62 \%$ of students in this study gained knowledge which made them safer for self-medication; being more careful when self-medicating and reading the package leaflet of self-medicated drug were the most frequent change in practice and recent attitude of students towards self-medication, respectively.

Similar results were obtained in Brazil where a high percentage of university students replied that they discouraged their friends and relatives from self-medication. Larger number of healthcare students discouraged their friends and relatives from self-medication (85.8 versus $76.6 \%$, resp.; $p<$ 0.001) [24].

In this study, younger age, female, medical, and evermarried students and those who have home pharmacy tended to self-medicate more than their peers with significant difference between them. Similarly, in Southwestern Nigeria, female students exhibited higher prevalence of selfmedication than their male counterpart. At the undergraduate levels, the prevalence of self-medication increased marginally from 1 st year to 5 th year students. Self-medication was significantly associated with age, gender, and students' level in the university at $p<0.001$ [33].

In Brazil, age, male sex, employment, having a partner, and having children were significantly associated with selfmedication among university students in the bivariate analysis. In the healthcare program, existence of a home pharmacy was significantly associated with self-medication. The same was for last year students from healthcare versus nonhealthcare programs $(p=0.01)$. Lastly, poor medication knowledge was significantly associated with less self-medication while being a first or last year student did not affect the outcome [24].

However, in Karachi, there was no significant difference between self-medication practices of medical and nonmedical students, males and females, or the year of study. Selfmedication rates were not significantly lower in students aware of its harmful effects $(p=0.21)$ [3]. Similarly, in Abbottabad, Pakistan, there was nonsignificant difference in self-medication between the two genders of university students [25].

Logistic regression analysis showed that being from urban area, being medical student, having good current health condition, being careless about health, and having drugs stored at home pharmacy were independent predictors for self-medicating $(\mathrm{OR}=1.4,2.2,2,0.5$, and 2.4, resp.).

In Brazil, sex, having children, illicit drug use, and having a home pharmacy were statistically associated with selfmedication among university students in the multivariate analysis. Poor medication knowledge was significantly associated with less self-medication [24]. Storage of medications at home with free access and easy visualization of drugs is a risk factor for self-medication [31].

\section{Limitations of This Study}

This study suffers some limitations. The questionnaire was self-reported which could have led to underreporting of selfmedication practices.

The structure of questionnaires could affect prevalence estimates; longer questionnaires could result in a higher prevalence of self-reported self-medication, whereas shorter questionnaires with open questions could result in a lower prevalence of self-reported self-medication within the same population [34].

\section{Conclusion}

In conclusion, our findings demonstrated that selfmedication is prevalent among Mansoura University students. Being from urban area, being medical student, having good current health condition, being careless about health, and having drugs stored at home pharmacy are independent risk factors for self-medication among them. Proper counseling and public health education together with strict regulations on drug advertisement and supply would be successful interventions.

\section{Recommendations}

The prevalence of self-medication practices is unexpectedly high whether among medical or nonmedical students. This could be attributed to the long waiting queues at clinics or hospitals and country poor regulations and relaxed laws, which manifest as weak control over both sale of medicines from pharmacy stores without doctor's prescription and advertisement which affects the youth decision to selfmedicate. Suggested solutions to combat this problem could include the following approaches: (i) health professionals should actively participate through counseling and public health education about problems that may arise from inappropriate use of medications, (ii) health facilities should be available to each individual with much less difficulties, and (iii) strict rules regarding pharmaceutical advertising and supply of medications without pharmacies' prescription should be laid down.

\section{Conflicts of Interest}

The authors declare that they have no conflicts of interest.

\section{References}

[1] J. L. Montastruc, H. Bagheri, T. Geraud, and M. Lapeyre-Mestre, "Pharmacovigilance of self-medication," Therapies, vol. 52, no. 2, pp. 105-110, 1997.

[2] F. S. V. T. Pereira, F. Bucaretchi, C. Stephan, and R. Cordeiro, "Self-medication in children and adolescents," Jornal de Pediatria, vol. 83, no. 5, pp. 453-458, 2007. 
[3] S. N. Zafar, R. Syed, S. Waqar et al., "Self-medication amongst university students of Karachi: prevalence, knowledge and attitudes," Journal of the Pakistan Medical Association, vol. 58, no. 4, pp. 214-217, 2008.

[4] S. Sarahroodi, A. Maleki-Jamshid, A. F. Sawalha, P. Mikaili, and L. Safaeian, "Pattern of self-medication with analgesics among Iranian University students in central Iran," Journal of Family and Community Medicine, vol. 19, no. 2, pp. 125-129, 2012.

[5] O. Ehigiator, C. Azodo, A. Ehizele, E. Ezeja, L. Ehigiator, and I. Madukwe, "Self-medication practices among dental, midwifery and nursing students," European Journal of General Dentistry, vol. 2, no. 1, pp. 54-57, 2013.

[6] S. M. Abay and W. Amelo, "Assessment of self-medication practices among medical, pharmacy, and health science students in Gondar University, Ethiopia," Journal of Young Pharmacists, vol. 2, no. 3, pp. 306-310, 2010.

[7] Z. Klemenc-Ketiš, Ž. Hladnik, and J. Kersnik, "A cross sectional study of sex differences in self-medication practices among university students in Slovenia," Collegium Antropologicum, vol. 35, no. 2, pp. 329-334, 2011.

[8] A. F. Sawalha, "A descriptive study of self-medication practices among Palestinian medical and nonmedical university students," Research in Social and Administrative Pharmacy, vol. 4, no. 2, pp. 164-172, 2008.

[9] Z. Klemenc-Ketis, Z. Hladnik, and J. Kersnik, "Self-medication among healthcare and non-healthcare students at university of Ljubljana, Slovenia," Medical Principles and Practice, vol. 19, no. 5, pp. 395-401, 2010.

[10] L. J. Burak and A. Damico, "College students' use of widely advertised medications," Journal of American College Health, vol. 49, no. 3, pp. 118-121, 2000.

[11] H. James, S. S. Handu, K. A. J. Al Khaja, and R. P. Sequeira, "Influence of medical training on self-medication by students," International Journal of Clinical Pharmacology and Therapeutics, vol. 46, no. 1, pp. 23-29, 2008.

[12] S. Ghosh, V. Vikas, A. Gupta, and R. Chaudhary, "Evaluation of the practice of self medication among college students in west Uttar Pradesh," International Journal of Pharma Professional's Research, vol. 1, no. 1, pp. 14-18, 2010.

[13] A. Hussain and A. Khanum, "Self-medication among university students of Islamabad, Pakistan-a preliminary study," Southern Med Review, vol. 1, no. 1, pp. 14-16, 2008.

[14] World Health Organization (WHO), The Safety of Medicines, 2005.

[15] A. I. D. Loyola Filho, M. F. Lima-Costa, and E. Uchôa, "Bambuí Project: a qualitative approach to self-medication," Cadernos de Saude Publica, vol. 20, no. 6, pp. 1661-1669, 2004.

[16] C. M. Hughes, J. C. McElnay, and G. F. Fleming, "Benefits and risks of self medication," Drug Safety, vol. 24, no. 14, pp. 10271037, 2001.

[17] N. F. A. El-Ezz and H. S. Ez-Elarab, "Knowledge, attitude and practice of medical students towards self medication at Ain Shams University, Egypt," Journal of Preventive Medicine and Hygiene, vol. 52, no. 4, pp. 196-200, 2011.

[18] A. Mostafa, A. Hany, E. Ayed et al., "Patterns of self-medication misuse among university students," International Journal of Healthcare Sciences, vol. 2, no. 2, pp. 180-186, 2015.

[19] G. Mitsi, E. Jelastopulu, H. Basiaris, A. Skoutelis, and C. Gogos, "Patterns of antibiotic use among adults and parents in the community: a questionnaire-based survey in a Greek urban population," International Journal of Antimicrobial Agents, vol. 25, no. 5, pp. 439-443, 2005.
[20] S. I. Al-Azzam, B. A. Al-Husein, F. Alzoubi, M. M. Masadeh, and M. A. S. Al-Horani, "Self-medication with antibiotics in Jordanian population," International Journal of Occupational Medicine and Environmental Health, vol. 20, no. 4, pp. 373-380, 2007.

[21] G. B. Gutema, D. A. Gadisa, Z. A. Kidanemariam et al., "Self-medication practices among health sciences students: the case of Mekelle University," Journal of Applied Pharmaceutical Science, vol. 1, no. 10, pp. 183-189, 2011.

[22] H. James, S. S. Handu, K. A. J. Al Khaja, S. Otoom, and R. P. Sequeira, "Evaluation of the knowledge, attitude and practice of self-medication among first-year medical students," Medical Principles and Practice, vol. 15, no. 4, pp. 270-275, 2006.

[23] D. Galato, L. D. M. Galafassi, G. M. Alano, and S. C. Trauthman, "Responsible self-medication: review of the process of pharmaceutical attendance," Brazilian Journal of Pharmaceutical Sciences, vol. 45, no. 4, pp. 625-633, 2009.

[24] M. G. Corrêa Da Silva, M. C. F. Soares, and A. L. MuccilloBaisch, "Self-medication in university students from the city of Rio Grande, Brazil," BMC Public Health, vol. 12, no. 1, article 339, 2012.

[25] H. Ullah, S. A. Khan, S. Ali et al., "Evaluation of self-medication amongst university students in Abbottabad, Pakistan; prevalence, attitude and causes," Acta Poloniae Pharmaceutica, vol. 70, no. 5, pp. 919-922, 2013.

[26] N. Bhattarai, D. Basyal, and N. Bhattarai, "Self medication practice among undergraduate pharmacy students in Kathmandu Valley, Nepal," International Journal of Pharma Sciences and Research, vol. 5, no. 11, pp. 737-746, 2014.

[27] V. Aljinović-Vučić, V. Trkulja, and Z. Lacković, "Content of home pharmacies and self-medication practices in households of pharmacy and medical students in Zagreb, Croatia: findings in 2001 with a reference to 1977," Croatian Medical Journal, vol. 46, no. 1, pp. 74-80, 2005.

[28] G. S. Lau, K. K. Lee, and C. T. Luk, "Self-medication among university students in Hong Kong," Asia-Pacific Journal of Public Health, vol. 8, no. 3, pp. 153-157, 1995.

[29] D. S. de Aquino, J. A. C. de Barros, and M. D. P. da Silva, "Selfmedication and health academic staff," Ciencia e Saude Coletiva, vol. 15, no. 5, pp. 2533-2538, 2010.

[30] C. Buke, M. Hosgor-Limoncu, S. Ermertcan et al., "Irrational use of antibiotics among university students," Journal of Infection, vol. 51, no. 2, pp. 135-139, 2005.

[31] M. J. Stasio, K. Curry, K. M. Sutton-Skinner, and D. M. Glassman, "Over-the-counter medication and herbal or dietary supplement use in college: dose frequency and relationship to self-reported distress," Journal of American College Health, vol. 56, no. 5, pp. 535-547, 2008.

[32] E. Abahussain, L. K. Matowe, and P. J. Nicholls, "Self-reported medication use among adolescents in Kuwait," Medical Principles and Practice, vol. 14, no. 3, pp. 161-164, 2005.

[33] K. P. Osemene and A. Lamikanra, "A study of the prevalence of self-medication practice among university students in southwestern Nigeria," Tropical Journal of Pharmaceutical Research, vol. 11, no. 4, pp. 683-689, 2012.

[34] H. Gama, S. Correia, and N. Lunet, "Effect of questionnaire structure on recall of drug utilization in a population of university students," BMC Medical Research Methodology, vol. 9, no. 1, article 45, 2009. 


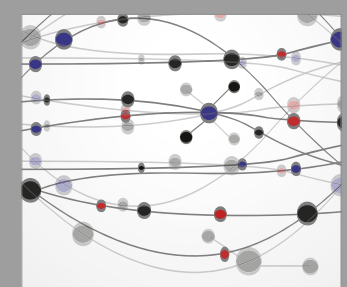

The Scientific World Journal
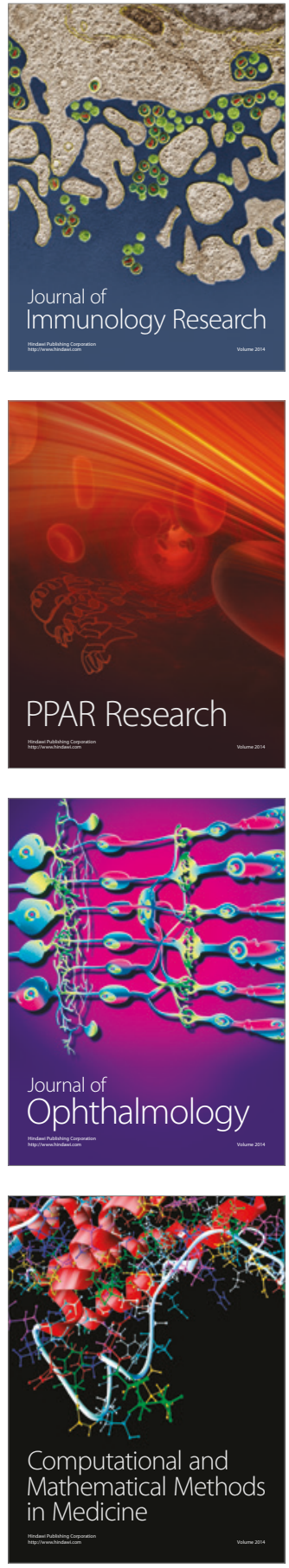

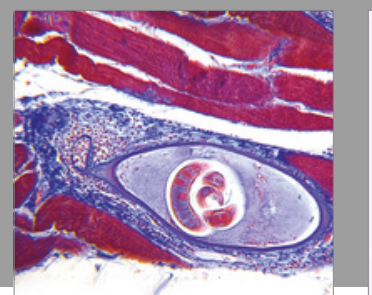

Gastroenterology Research and Practice
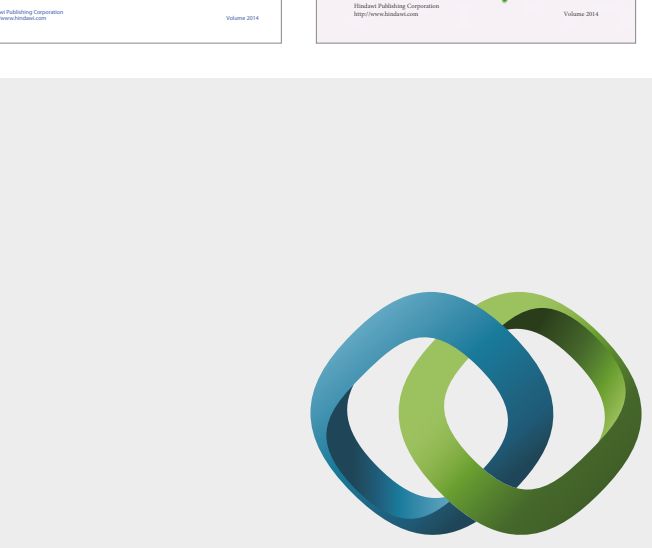

\section{Hindawi}

Submit your manuscripts at

https://www.hindawi.com
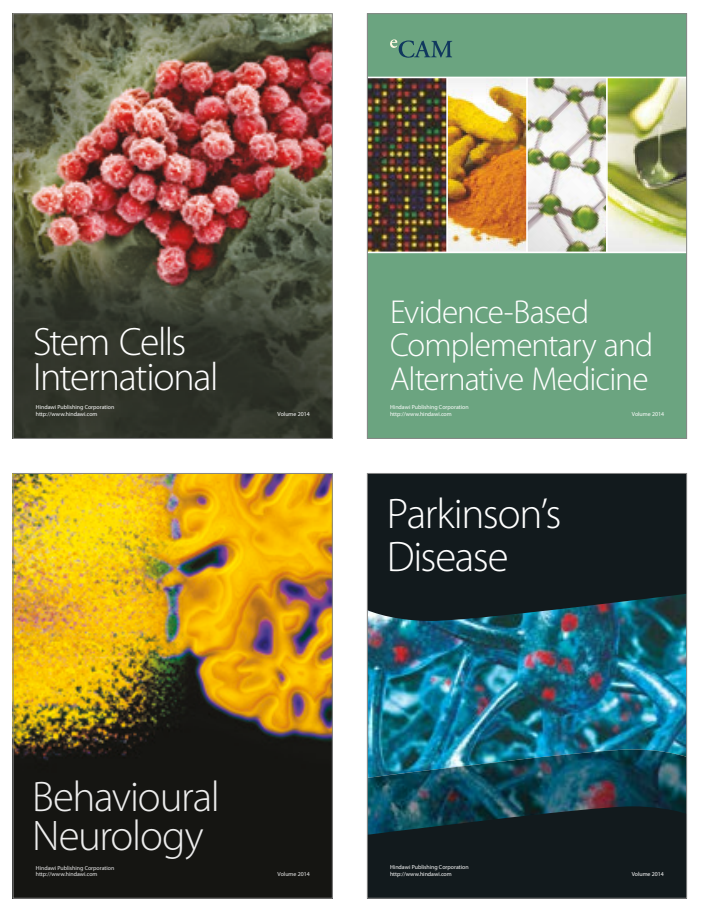
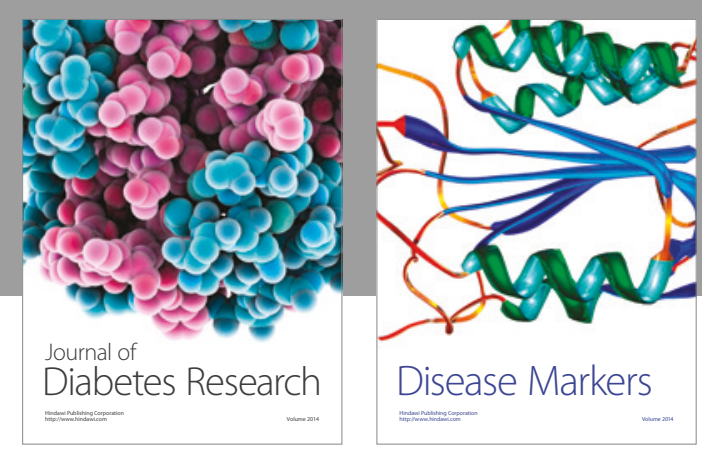

Disease Markers
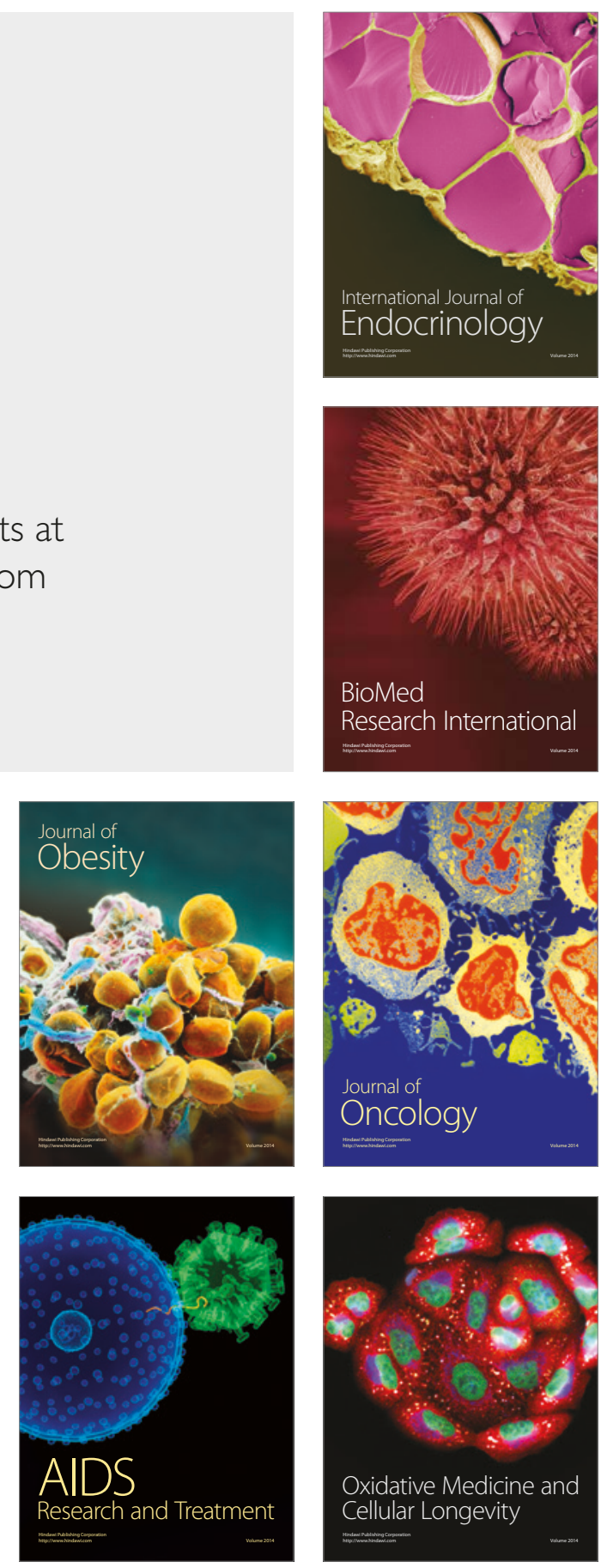